\title{
Inhibition of Calotropis procera Latex-Induced Inflammatory Hyperalgesia by Oxytocin and Melatonin
}

\author{
Biswa M. Padhy and Vijay L. Kumar \\ Department of Pharmacology, All India Institute of Medical Sciences, Ansari Nagar, New Delhi 110029, India
}

Received 15 July 2005; accepted 25 August 2005

\begin{abstract}
The latex of the wild growing plant Calotropis procera produces inflammation of the skin and mucous membranes upon accidental exposure. On local administration it elicits an intense inflammatory response due to the release of histamine and prostaglandins that is associated with hyperalgesia. In the present study we have evaluated the anti-inflammatory and antinociceptive activity of oxytocin and melatonin against rat paw edema induced by dried latex (DL) of $C$ procera and compared it with that against carrageenan-induced paw edema. Aqueous extract of DL of $C$ procera or carrageenan (1\%) was injected into the subplantar surface of the rat paw and the paw volume was measured at $0,1,2,3,4,6,10$, and 24 hours. The associated hyperalgesic response and functional impairment were also evaluated concomitantly by dorsal flexion pain test, motility test, and stair climbing ability test. The inhibitory effect of oxytocin and melatonin on edema formation and hyperalgesic response was compared with dexamethasone. DLinduced edema formation was maximum at 2 hours and was associated with decreased pain threshold and functional impairment. Treatment with melatonin significantly attenuated the edematous response while both oxytocin and melatonin increased the pain threshold and improved functional parameters. Both oxytocin and melatonin significantly inhibited the hyperalgesia associated with DL-induced paw edema. Oxytocin was found to be as effective as melatonin in ameliorating the hyperalgesic response. However, it was found to be less effective than melatonin in attenuating edema formation.
\end{abstract}

\section{INTRODUCTION}

The proinflammatory property of latex of Calotropis procera, a wild growing plant belonging to family Asclepiadaecae is well documented [1]. Accidental exposure of the skin and mucous membraneto the latex has been reported to cause contact dermatitis, keratitis, and toxic iridocyclitis $[2,3,4]$. When administered locally, the latex induces an intense inflammatory response characterized by increased vascular permeability, edema, and profound cellular infiltration. Studies have shown that the early phase of this response is mediated partly by the histamine present in the latex and partly by release of histamine from mast cells [5]. In addition, synthesis and release of prostaglandins through induction of COX-2 also contributes to the overall inflammatory process [6]. Both histamine and prostaglandins are well known sensitizers of the nociceptors and are involved in inflammatory hyperalgesia $[7,8,9]$. Therefore, latex-induced inflammation could be effectively ameliorated by antiseroton-

Correspondence and reprint requests to Vijay L. Kumar, Department of Pharmacology, All India Institute of Medical Sciences, Ansari Nagar, New Delhi 110029, India; kumarv198@hotmail.com ergic and antihistaminic drug cyproheptadine and non steroidal anti-inflammatory drugs like rofecoxib and diclofenac [10].

The inflammation and associated hyperalgesia elicit an adaptogenic response, mediated through various neuroendocrine modulatory pathways. In this regard, the neurohormones oxytocin and melatonin have been reported to exhibit antinociceptive and antiinflammatory properties. Both oxytocin and melatonin inhibit carrageenin-induced inflammatory hyperalgesia in rats $[11,12,13,14]$. Hence the present study was carried out to evaluate the efficacy of melatonin, oxytocin, and standard anti-inflammatory drug dexamethasone against inflammatory and hyperalgesic responses induced by latex of $C$ procera and to compare it with that against carrageenan.

\section{MATERIALS AND METHODS}

\section{Plant material and drugs}

The latex of $C$ procera was collected from the aerial parts of the plant growing in the wild and was dried under shade (DL). It was then triturated in normal saline (NS) and centrifuged to obtain a clear solution. The plant was identified by the Raw Materials, Herbarium 
and Museum Division, National Institute of Science and Communication, New Delhi, where a voucher specimen is preserved (voucher no PID 1739). The drugs used in this study were obtained from Ranbaxy Laboratories Ltd (New Delhi, India) (dexamethasone); Novartis (Mumbai, India) (oxytocin), and Sigma-Aldrich Inc (St Louis, USA) (melatonin).

\section{Animals}

The study was carried out on male Wistar rats weighing $150-180 \mathrm{~g}$. They were kept at ambient temperature and had free access to water and diet. All experimental procedures described were carried out in accordance with the guidelines of Institutional Animal Ethics Committee.

\section{Induction of paw edema}

Edema was induced in the right-hind paw of rats by subplantar injection of $0.1 \mathrm{~mL}$ of $1 \%$ solution of DL or carrageenan. The paw volume was measured up to a fixed mark on the lateral malleolus at $0,1,2,3,4,6,10$, and 24 hours using a plethysmometer. Edema volume was calculated at each time interval as the difference from paw volume at 0 hour. Dexamethasone $(1 \mathrm{and} 10 \mathrm{mg} / \mathrm{kg}$; dex 1 and dex10), oxytocin $(0.1$ and $1 \mathrm{mg} / \mathrm{kg}$; oxy 0.1 and oxy 1$)$, and melatonin (5 and $50 \mathrm{mg} / \mathrm{kg}$; mel5 and mel50) were administered subcutaneously 30 minutes before injecting inflammagen. The effect of the drugs at each time interval was evaluated on the stair climbing ability, motility, and pain produced by dorsal flexion.

\section{Stair climbing ability test}

The overnight fasted animals were trained for one week to climb a staircase with steps at 5,10 , and $15 \mathrm{~cm}$ having water at the second and food at the third step $[15,16]$. The climbing ability of the rats in above groups was scored 0 if the rats did not climb; 1 , if the rats climbed onto step $1 ; 2$, if the rats climbed onto step 2 ; and 3 , if the rat could climb all the three steps.

\section{Motility test}

The motility pattern of the rats was observed for a period of 5 minutes and scored 0 , if the rat walked with difficulty and avoided touching the toes of the inflamed paw to the floor; 1 , if the rat walked with little difficulty, but with toe touching the floor; 2 , if the rat walked easily $[15,16]$.

\section{Dorsal flexion pain test}

The ankle joint was flexed dorsally until the toe touched the anterior part of the leg. The test was performed five times with an intertest interval of 5 seconds and the pain was scored 0 , if there was no squeaking and no leg withdrawal; 1 , if there was either squeaking or leg withdrawal; 2, if both squeaking and leg withdrawal were present [15].

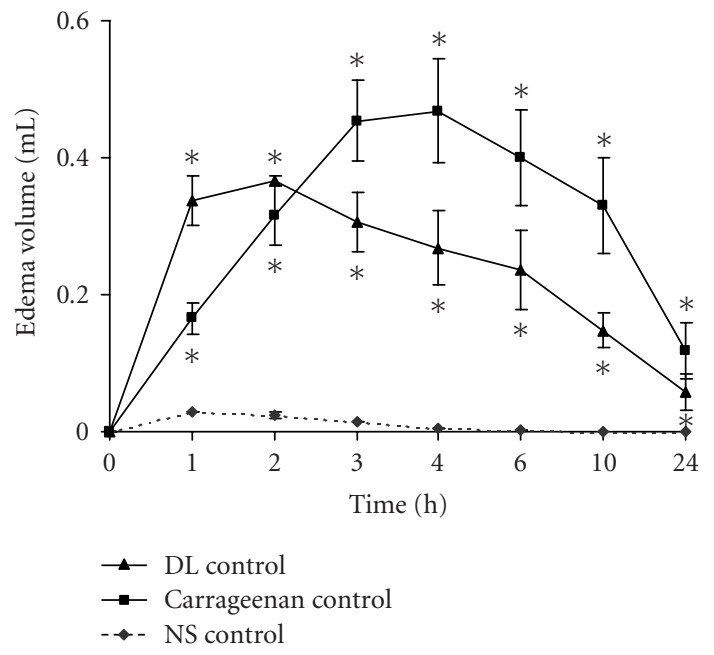

FIgURE 1. Time course for DL- and carrageenan-induced edema formation. Aqueous solution of $\mathrm{DL}$ of $C$ procera $(0.1 \mathrm{~mL}$ of $1 \%$ solution), carrageenan $(0.1 \mathrm{~mL}$ of $1 \%$ solution $)$, and NS $(0.1 \mathrm{~mL})$ were injected into the subplantar surface of the rat paw and edema volume was measured at 1, 2, 3, 4, 6, 10, and 24 hours $(n=6) .{ }^{*} P<.05$ versus NS control.

\section{Statistical analysis}

The value for edema volume is expressed as mean \pm standard error of themean of five observations and ANOVA followed by post hoc test was used tocompare the groups. The stair climbing ability test, motility, and pain following dorsal flexion are expressed as median scores and the Kruscal-Wallis test was used to compare the groups. The statistical analysis was carried out by the version 10 of the SPSS program and the value of $P<.05$ was considered as statistically significant.

\section{RESULTS}

\section{Time course of DL- and carrageenan-induced paw edema}

Subplantar injection of DL produced an intense inflammatory response in the hind paw of rats that was discernable within 15 minutes, reached a maximum at 1 hour, and was maintained until 2 hours. The paw edema produced by carrageenan was comparatively slower in onset and the peak effect was attained between 3 and 4 hours. Injection of NS into the subplantar region of the hind paw produced a marginal increase in paw volume between 1 and 2 hours (Figure 1).

\section{Inhibitory effect of drugs against DL- and carrageenan-induced paw edema}

The effect of various drugs on DL- and carrageenaninduced paw edema was studied at 2 hours and 4 hours, respectively. The drugs were administered by subcutaneous route 30 minutes before injecting the inflammagen. 
TABLE 1. Effect of various drugs on DL- and carrageenan-induced paw edema. Edema was induced by injecting $0.1 \mathrm{~mL}$ of $1 \%$ solution of DL or carrageenan into subplantar surface of right-hind paw. The drugs were administered subcutaneously 30 minutes before injecting inflammagen. The edema volume was calculated at the time of peak inflammation ( 2 hours for DL and 4 hours for carrageenan). The values given are mean \pm standard error of the mean $(n=6) .{ }^{*} P<.05,{ }^{* *} P<.01$ compared with respective control.

\begin{tabular}{lcccc}
\hline \multirow{2}{*}{ Treatment groups } & \multicolumn{2}{c}{ DL-induced paw edema } & \multicolumn{2}{c}{ Carrageenan-induced paw edema } \\
\cline { 2 - 5 } & $\begin{array}{l}\text { Edema volume }(\mathrm{mL}) \\
\text { Mean } \pm \text { SEM }\end{array}$ & $\begin{array}{l}\text { \% inhibition of } \\
\text { edema formation }\end{array}$ & $\begin{array}{l}\text { Edema volume (mL) } \\
\text { Mean } \pm \text { SEM }\end{array}$ & $\begin{array}{c}\text { \% inhibition of } \\
\text { edema formation }\end{array}$ \\
\hline Normal saline & $0.02 \pm 0.01$ & - & $0.01 \pm 0.01$ & - \\
Control & $0.37 \pm 0.01$ & - & $0.47 \pm 0.07$ & 36 \\
$\begin{array}{l}\text { Dexamethasone } \\
(1 \mathrm{mg} / \mathrm{kg})\end{array}$ & $0.31 \pm 0.08$ & 16 & $0.30 \pm 0.06^{*}$ & 64 \\
$\begin{array}{l}\text { Dexamethasone } \\
(10 \mathrm{mg} / \mathrm{kg})\end{array}$ & $0.20 \pm 0.02^{*}$ & 46 & $0.17 \pm 0.02^{* *}$ \\
$\begin{array}{l}\text { Oxytocin } \\
(0.1 \mathrm{mg} / \mathrm{kg})\end{array}$ & $0.30 \pm 0.02$ & 19 & $0.42 \pm 0.06$ & 11 \\
$\begin{array}{l}\text { Oxytocin } \\
(1 \mathrm{mg} / \mathrm{kg})\end{array}$ & $0.25 \pm 0.03^{*}$ & 32 & $0.28 \pm 0.04^{*}$ \\
$\begin{array}{l}\text { Melatonin } \\
(5 \mathrm{mg} / \mathrm{kg})\end{array}$ & $0.25 \pm 0.01^{*}$ & 32 & $0.32 \pm 0.01^{*}$ \\
$\begin{array}{l}\text { Melatonin } \\
(50 \mathrm{mg} / \mathrm{kg})\end{array}$ & $0.15 \pm 0.01^{* *}$ & 59 & $0.18 \pm 0.01^{* *}$ \\
\hline
\end{tabular}

Both oxytocin and melatonin produced a dose-dependent decrease in edema formation by DL and carrageenan. Oxytocin at $1 \mathrm{mg} / \mathrm{kg}$ produced $32 \%$ and $40 \%$ inhibition in DL- and carrageenan-induced paw edema, respectively, while melatonin $50 \mathrm{mg} / \mathrm{kg}$ produced $59 \%$ and $62 \%$ inhibition. The inhibitory effect of melatonin against DL-induced edema was more pronounced than dexamethasone $10 \mathrm{mg} / \mathrm{kg}$ (59\% versus $46 \%$ inhibition). On the other hand the inhibitory effect of melatonin against carrageenan-induced paw edema was comparable to that of dexamethasone $10 \mathrm{mg} / \mathrm{kg}$ (62\% versus $64 \%$ inhibition) (Table 1).

\section{Antinociceptive effect of drugs against DL- and carrageenan-induced inflammatory hyperalgesia}

The edematogenic effect of DL and carrageenan was associated with hyperalgesia as revealed by dorsal flexion pain (DFP) score of 8 and 7 , respectively, against 0 in NS-treated rats (Figures $2 \mathrm{a}$ and $2 \mathrm{~b}$ ). Oxytocin, melatonin, and dexamethasone were equieffective in ameliorating inflammatory hyperalgesia induced by DL at the time of peak inflammation and DFP score of 3 was obtained. The antinociceptive effect of these drugs persisted up to 24 hours where dexamethasone was found to be most effective. In case of carrageenan-induced inflammatory hyperalgesia, dexamethasone was found to be slightly more effective than oxytocin and melatonin at peak inflammation (DFP scores 3, 4, 4 against 7 in control). The antinociceptive effect of oxytocin was more pronounced than melatonin and dexamethasone at 24 hours (Figures $2 \mathrm{a}$ and $2 \mathrm{~b})$.

\section{Effect of drugs against functional impairment associated with DL-and carrageenan-induced inflammatory hyperalgesia}

The hyperalgesia induced by DL and carrageenan resulted in functional impairment where the motility of the rats was affected (median motility score 0 ). Both oxytocin and melatonin dose dependently, prevented impairment in motility and a median motility score of 1 was attained. Dexamethasone on the other hand was more effective and rats treated with dexamethasone $(10 \mathrm{mg} / \mathrm{kg})$ could walk without difficulty in a manner similar to those injected with NS. We further tested the ability of the animals to climb a staircase at the time of peak inflammation. The animals in the DL and carrageenan control groups were unable to climb the steps and exhibited a median score of 0 against animals in the NS-treated group with a maximum score of 3 . Both oxytocin and melatonin produced dose-dependent improvement in the stair climbing ability in case of DL as well as carrageenan-induced inflammatory hyperalgesia. However, the effect of oxytocin was more pronounced in case of carrageenan-induced inflammatory hyperalgesia and median score of 2 was attained. Melatonin on the other hand was more effective in DLinduced inflammatory hyperalgesia and rats treated with $50 \mathrm{mg} / \mathrm{kg}$ of melatonin could climb all the steps and a score of 3 was attained (Table 2).

\section{DISCUSSION}

Neuroendocrine modulatory pathways play an important role in the adaptogenic response associated with 


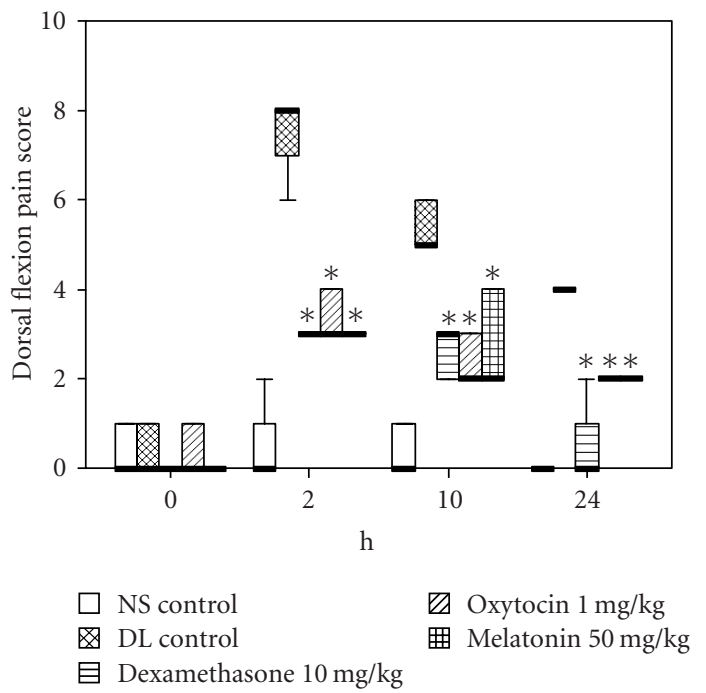

(a)

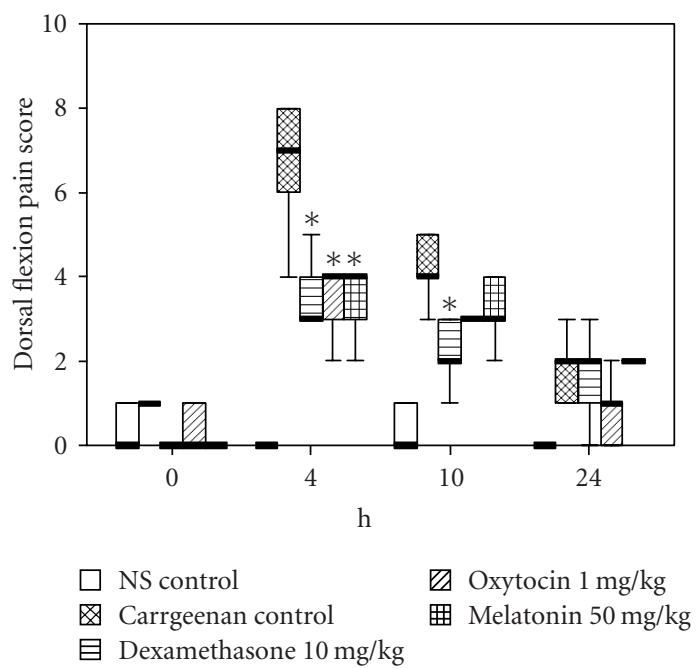

(b)

FIGURE 2. Antihyperalgesic effect of various drugs on (a) DL- and (b) carrageenan-induced inflammatory hyperalgesia. Edema was induced by injecting $0.1 \mathrm{~mL}$ of $1 \%$ solution of DL or carrageenan into the subplantar surface of right-hind paw. The drugs were administered subcutaneously 30 minutes before injecting inflammagen. Dorsal flexion pain score was recorded at different time intervals $(n=6)$. The data is illustrated as box plots where bold line represents median values, boxes represent interquartile ranges (25th and 75th percentiles), and whiskers represent extreme values. NS control. ${ }^{*} P<.05$ versus respective control.

inflammatory hyperalgesia. In the present study we have evaluated the efficacy of melatonin, oxytocin, and dexamethasone against inflammation and hyperalgesia induced by latex of $C$ procera and compared it with that against carrageenan. The inflammatory response elicited by DL was rapid in onset, with a peak effect occurring between 1-2 hours and was associated with maximum hyperalgesia as indicated by dorsal flexion pain test. Carrageenan on the other hand elicited peak inflammation and hyperalgesia at 3-4 hours. As reported earlier, the inflammatory response induced by DL is mediated primarily by the histamine present in it and also by release of histamine from the mast cells [5]. On the other hand, carrageenan induced inflammatory and hyperalgesic response is mainly due to synthesis and release of prostaglandins [17]. In our study oxytocin and melatonin produced significant inhibition in edema formation induced by both DL and carrageenan, and melatonin was more effective in this regard. Both oxytocin and melatonin were equieffective in ameliorating pain as revealed by dorsal flexion pain test, and the motility and staircase climbing ability of the animals was significantly improved. Oxytocin, a commonly used uterotonic agent, might be producing antinociceptive effect due to its anti-inflammatory property that has been shown to be comparable to dexamethasone [12]. The anti-inflammatory effect of oxytocin has been reported to be mediated through the inhibition of neutrophil-dependent oxidative damage [18]. Besides, oxytocin has also been shown to exhibit antinociceptive effect by interacting with oxytocin receptors and mu and kappa opioid receptors localized in the dorsal horn of the spinal cord $[19,20]$. Morever, oxytocin has been
TABLE 2. Effect of various drugs on impairment in motility and stair climbing ability (SCA) associated with DL- and carrageenan-induced inflammation. Edema was induced by injecting $0.1 \mathrm{~mL}$ of $1 \%$ solution of DL or carrageenan into subplantar surface of right-hind paw. The drugs were administered subcutaneously 30 minutes before injecting inflammagen. Motility and staircase climbing ability was observed at the time of peak inflammation ( 2 hours for DL and 4 hours for carrageenan). The values given are median score $(n=6) .{ }^{*} P<.01$ versus respective control.

\begin{tabular}{lcccc}
\hline \multirow{2}{*}{ Treatment group } & \multicolumn{2}{c}{ DL } & \multicolumn{2}{c}{ Carrageenan } \\
\cline { 2 - 5 } & Motility & SCA & Motility & SCA \\
\hline Normal saline & 2 & 3 & 2 & 3 \\
Control & 0 & 0 & 0 & 0 \\
$\begin{array}{l}\text { Dexamethasone } \\
(1 \mathrm{mg} / \mathrm{kg})\end{array}$ & 0 & 0 & 0 & $1^{*}$ \\
$\begin{array}{l}\text { Dexamethasone } \\
(10 \mathrm{mg} / \mathrm{kg})\end{array}$ & $2^{*}$ & $3^{*}$ & $2^{*}$ & $3^{*}$ \\
$\begin{array}{l}\text { Oxytocin } \\
(0.1 \mathrm{mg} / \mathrm{kg})\end{array}$ & 0 & 0 & 0 & 0 \\
$\begin{array}{l}\text { Oxytocin } \\
(1 \mathrm{mg} / \mathrm{kg})\end{array}$ & $1^{*}$ & $1^{*}$ & $1^{*}$ & $2^{*}$ \\
$\begin{array}{l}\text { Melatonin } \\
(5 \mathrm{mg} / \mathrm{kg})\end{array}$ & 0 & $1^{*}$ & 0 & $1^{*}$ \\
$\begin{array}{l}\text { Melatonin } \\
(50 \mathrm{mg} / \mathrm{kg})\end{array}$ & $1^{*}$ & $3^{*}$ & $1^{*}$ & $2^{*}$ \\
\hline
\end{tabular}

successfully used in the treatment of diabetic foot lesions and intractable cancer pain $[21,22]$. 
It is interesting to note that the antiedematogenic effect of melatonin was more pronounced than that of dexamethasone against DL-induced inflammation while it was comparable in case of carrageenan-induced inflammation. The higher antiedematogenic efficacy of melatonin compared to dexamethasone against DL-induced paw edema suggests that melatonin could be acting by inhibiting histamine-mediated inflammatory response. In a recent study melatonin, an agent affecting the circadian rhythm, has been shown to be more effective than corticosteroids in reducing histamine-induced oxidative damage [23]. Further, Gitto et al have also shown that melatonin significantly reduces mortality in neonatal sepsis by preventing oxidative damage [24]. Like corticosteroids, melatonin also exhibits anti-inflammatory properties through inhibition of COX-2, iNOS and proinflammatory cytokines TNF- $\alpha$ and INF- $\gamma[25,26,27$, 28]. Although dexamethasone was less effective as an anti-inflammatory agent, it was as effective as oxytocin and melatonin in ameliorating DL-induced hyperalgesia probably due to its inherent analgesic property [29]. The anti-inflammatory and antinociceptive effect of the drugs tested in this study was further substantiated by their ability to prevent functional impairment.

Thus, our study indicates that DL-induced edema is effectively inhibited by melatonin whereas associated hyperalgesia is equally inhibited by both oxytocin and melatonin and both these drugs could be used in inflammatory and painful conditions.

\section{REFERENCES}

[1] Singh H, Kumar S, Dewan S, Kumar VL. Inflammation induced by latex of Calotropis procera-a new model to evaluate anti-inflammatory drugs. J Pharmacol Toxicol Methods. 2000;43(3):219-224.

[2] Handa F, Sadana JK, Sharma PK. Allergic contact dermatitis due to the plant Calotropis procera (Vern: AK). A case report. Indian J Dermatol. 1984;29(3):27-29.

[3] Al-Mezaine HS, Al-Rajhi AA, Al-Assiri A, Wagoner MD. Calotropis procera (ushaar) keratitis. Am J Ophthalmol. 2005;139(1):199-202.

[4] Biedner B, Rothkoff L, Witztum A. Calotropis procera (Sodom apple) latex keratoconjunctivitis. Isr J Med Sci. 1977;13(9):914-916.

[5] Shivkar YM, Kumar VL. Histamine mediates the pro-inflammatory effect of latex of Calotropis procera in rats. Mediators Inflamm. 2003;12(5):299-302.

[6] Kumar VL, Shivkar YM. Involvement of prostaglandins in inflammation induced by latex of Calotropis procera. Mediators Inflamm. 2004;13(3):151-155.

[7] Di Rosa M, Giroud JP, Willoughby DA. Studies on the mediators of the acute inflammatory response induced in rats in different sites by carrageenan and turpentine. J Pathol. 1971;104(1):15-29.
[8] Guay J, Bateman K, Gordon R, Mancini J, Riendeau D. Carrageenan-induced paw edema in rat elicits a predominant prostaglandin E2 (PGE2) response in the central nervous system associated with the induction of microsomal PGE2 synthase-1. J Biol Chem. 2004;279(23):24866-24872.

[9] Juan H. Dependence of histamine-evoked nociception on prostaglandin release. Agents Actions. 1981;11(6-7):706-710.

[10] Sehgal R, Kumar VL. Calotropis procera latex-induced inflammatory hyperalgesia-effect of antiinflammatory drugs. Mediators Inflamm. 2005;2005 (4):216-220.

[11] Yu SQ, Lundeberg T, Yu LC. Involvement of oxytocin in spinal antinociception in rats with inflammation. Brain Res. 2003;983(1-2):13-22.

[12] Petersson M, Wiberg U, Lundeberg T, UvnasMoberg K. Oxytocin decreases carrageenan induced inflammation in rats. Peptides. 2001;22(9):14791484.

[13] El-Shenawy SM, Abdel-Salam OM, Baiuomy AR, El-Batran S, Arbid MS. Studies on the antiinflammatory and anti-nociceptive effects of melatonin in the rat. Pharmacol Res. 2002;46(3):235-243.

[14] Bilici D, Akpinar E, Kiziltunc A. Protective effect of melatonin in carrageenan-induced acute local inflammation. Pharmacol Res. 2002;46(2):133-139.

[15] De Castro Costa M, De Sutter P, Gybels J, Van Hees J. Adjuvant-induced arthritis in rats: a possible animal model of chronic pain. Pain. 1981;10(2):173-185.

[16] Wang Y, Huang C, Cao Y, Han JS. Repeated administration of low dose ketamine for the treatment of monoarthritic pain in the rat. Life Sci. 2000;67(3):261-267.

[17] Dawson J, Sedgwick AD, Edwards JC, Lees P. A comparative study of the cellular, exudative and histological responses to carrageenan, dextran and zymosan in the mouse. Int J Tissue React. 1991;13(4):171-185.

[18] Iseri SO, Sener G, Saglam B, Gedik N, Ercan F, Yegen BC. Oxytocin ameliorates oxidative colonic inflammation by a neutrophil-dependent mechanism. Peptides. 2005;26(3):483-491.

[19] Ge Y, Lundeberg T, Yu LC. Blockade effect of mu and kappa opioid antagonists on the anti-nociception induced by intra-periaqueductal grey injection of oxytocin in rats. Brain Res. 2002;927(2):204-207.

[20] Reiter MK, Kremarik P, Freund-Mercier MJ, Stoeckel ME, Desaulles E, Feltz P. Localization of oxytocin binding sites in the thoracic and upper lumbar spinal cord of the adult and postnatal rat: a histoautoradiographic study. Eur J Neurosci. 1994;6(1):98-104.

[21] Gavrilenko VG, Esipov VK, Sivozhelezov KG. Morphological characteristic of wound healing process in patients with diabetic purulent-necrotic foot lesion treated with oxytocin [in Russian]. Morfologiia. 2003;124(5):24-27. 
[22] Madrazo I, Franco-Bourland RE, Leon-Meza VM, Mena I. Intraventricular somatostatin-14, arginine vasopressin, and oxytocin: analgesic effect in a patient with intractable cancer pain. Appl Neurophysiol. 1987;50(1-6):427-431.

[23] Ucuncu H, Aktan B, Ozabacigil F, Buyukokuroglu ME, Akyuz M, Altas E. Protective effect of melatonin on experimental otitis media with effusion in guinea pigs. Ann Clin Lab Sci. 2004;34(3):341-346.

[24] Gitto E, Karbownik M, Reiter RJ, et al. Effects of melatonin treatment in septic newborns. Pediatr Res. 2001;50(6):756-760.

[25] Cuzzocrea S, Costantino G, Mazzon E, Caputi AP. Regulation of prostaglandin production in carrageenan-induced pleurisy by melatonin. J Pineal Res. 1999;27(1):9-14.

[26] Gilad E, Wong HR, Zingarelli B, et al. Melatonin inhibits expression of the inducible isoform of nitric oxide synthase in murine macrophages: role of inhibition of NFkappaB activation. FASEB J. 1998;12(9):685-693.

[27] Sacco S, Aquilini L, Ghezzi P, Pinza M, Guglielmotti A. Mechanism of the inhibitory effect of melatonin on tumor necrosis factor production in vivo and in vitro. Eur J Pharmacol. 1998;343(2-3):249-255.

[28] Di Stefano A, Paulesu L. Inhibitory effect of melatonin on production of IFN $\gamma$ or TNF $\alpha$ in peripheral blood mononuclear cells of some blood donors. J Pineal Res. 1994;17(4):164-169.

[29] Bogdanov AI, Yarushkina NI. Mechanisms of the effects of adrenocorticotropic hormone on pain sensitivity in rats. Neurosci Behav Physiol. 2003;33(8): 795-798. 


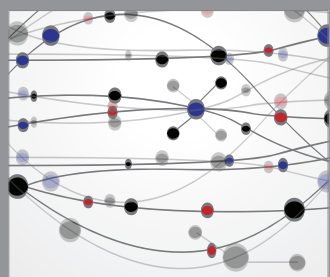

The Scientific World Journal
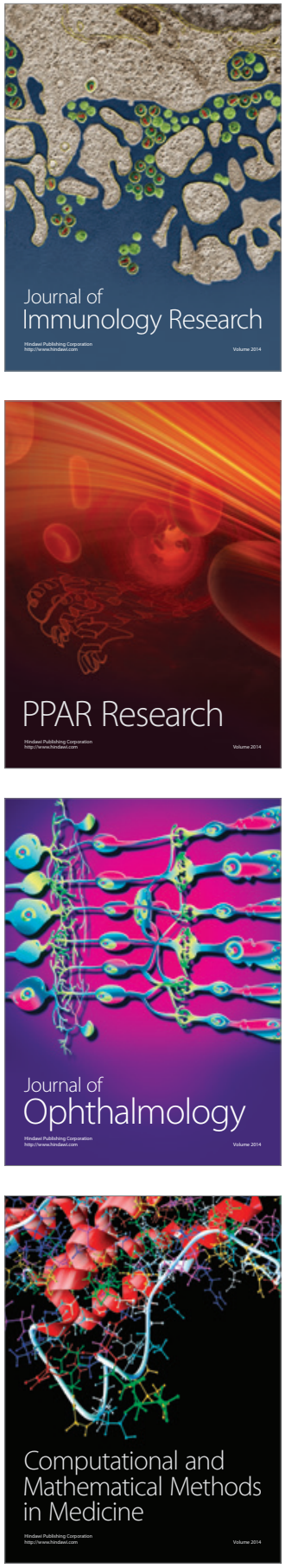

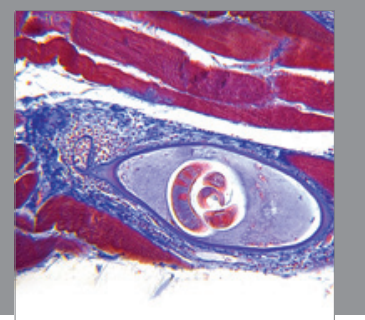

Gastroenterology

Research and Practice
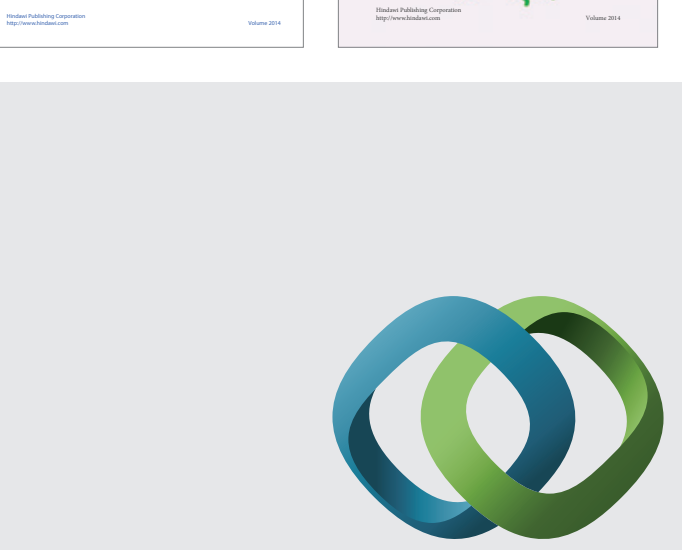

\section{Hindawi}

Submit your manuscripts at

http://www.hindawi.com
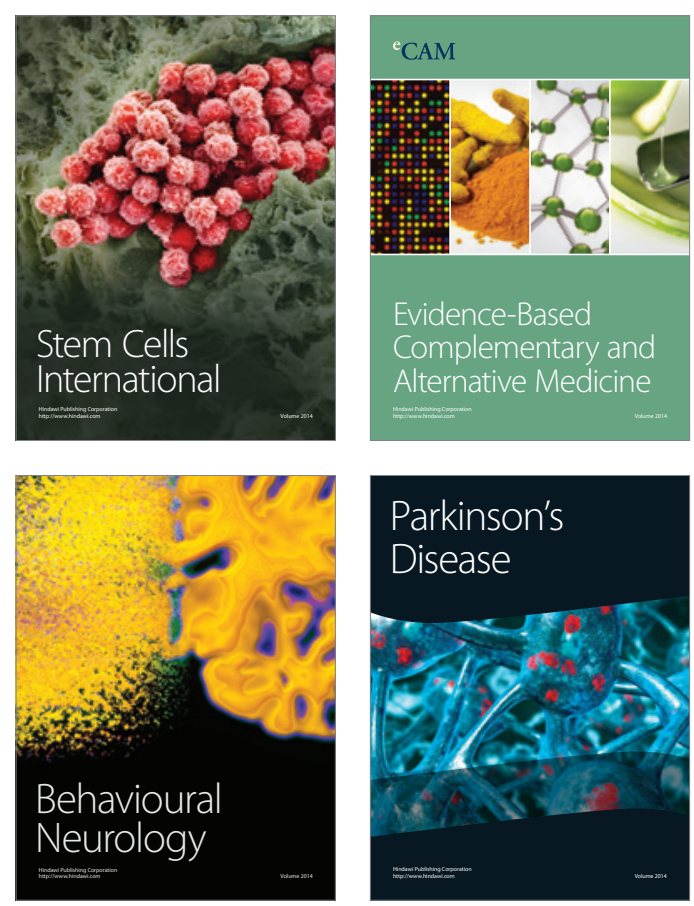

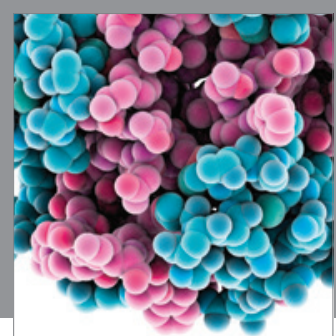

Journal of
Diabetes Research

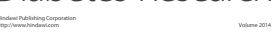

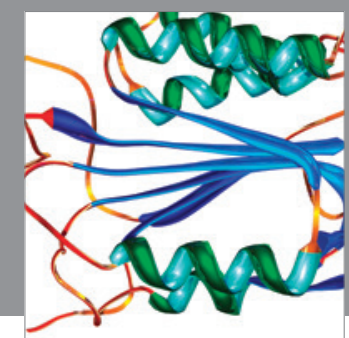

Disease Markers
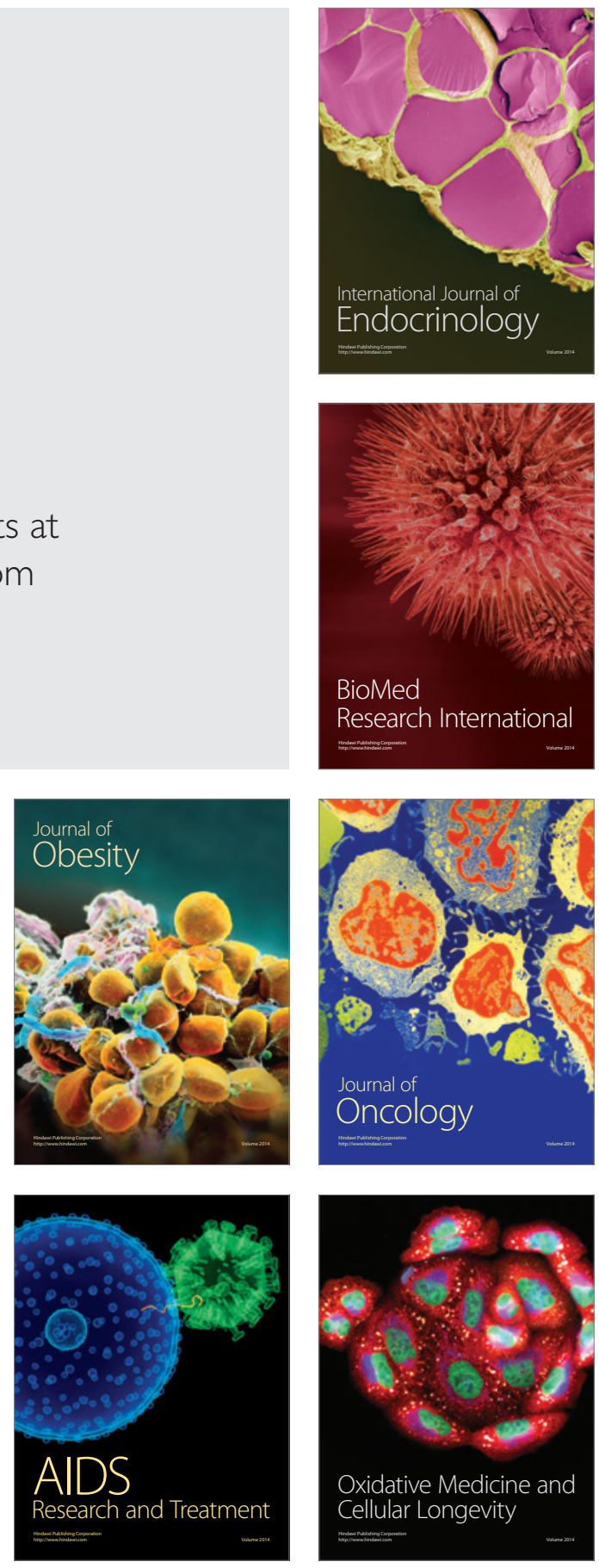